\title{
Rubella vaccination of schoolgirls: factors affecting vaccine uptake
}

\author{
CATHERINE S PECKHAM, W C MARSHALL, J A DUDGEON
}

British Medical fournal, 1977, 1, 760-761

\section{Summary}

In a national sample of 16-year-old girls who were aged 12 when the rubella vaccine programme was implemented in $1970,71 \%$ were reported to have received rubella vaccine. There was a high regional disparity in the uptake of rubella vaccine: $81 \%$ of girls living in Scotland had been vaccinated but only $61 \%$ of girls living in Wales. Similarly there was a difference in reported vaccine uptake according to the family social background, the lowest proportion vaccinated came from professional and unskilled manual families. Girls attending independent schools also had a lower vaccine uptake than girls in schools maintained by the local educational authorities. If rubella immunisation is to be effective uptake of vaccine must increase to almost $100 \%$.

\section{Introduction}

Rubella vaccines became available in Britain in 1970, and in the same year a selective vaccination programme was introduced in which girls between their 11th and 14th birthdays were offered vaccine at school without preliminary serological tests for susceptibility to rubella. In the first phase priority was given to the older girls-that is, those aged $13 .{ }^{1}$ Further recommendations were made by the Joint Committee on Vaccination and Immunisation to include certain "at risk" groups of adult women of childbearing age such as schoolteachers, nurses, and doctors, and women in the postpartum period who were identified by serological tests to be susceptible to rubella. ${ }^{23}$

The National Child Development Study, which is a longitudinal study of all children in England, Scotland, and Wales born in one week in March 1958, ${ }^{4}$ provided us with an opportunity to examine the uptake of rubella vaccine by 16 -year-old schoolgirls who were 12 when the rubella vaccine programme was first introduced.

\section{Source of information and results}

Vaccination of schoolgirls is carried out through the school health service. At the follow-up of 16 -year-old children in the National

National Children's Bureau, London EC1

CATHERINE S PECKHAM, MD, MFCM, senior medical research officer

Department of Microbiology, Institute of Child Health, London WCIN 1EH

W C MARSHALL, MD, DCH, senior lecturer

J A DUDGEON, FRCP, FRCPATH, professor
Child Development Study ${ }^{5}$ a medical examination form was completed by school doctors for 11686 children, 5541 of whom were girls. The results of a physical examination and details of the child's medical history, including a question whether the child had been vaccinated against rubella, were available. This information was obtained from interviews with the girls or their parents and from school medical records, which were available for the majority. Of the 5541 girls with completed medical forms, information on rubella vaccine uptake was available for 5097. For the remaining $444\left(8^{\circ} \%\right)$ it was not known if rubella vaccine had been given or the question had not been answered.

The reported uptake of rubella vaccine was examined by region, social class (the latter being defined according to the father's occupation $\left.^{6}\right)$ and the type of school attended. Of the 5097 girls, $3621(71 \%)$ were reported to have received rubella vaccine but there were considerable regional differences in vaccine uptake (see figure). The highest proportion of girls vaccinated was in Scotland and the South of England, and the lowest was in the North of England and Wales.

When the uptake of rubella vaccine was examined according to the child's socioeconomic background, the highest proportion of

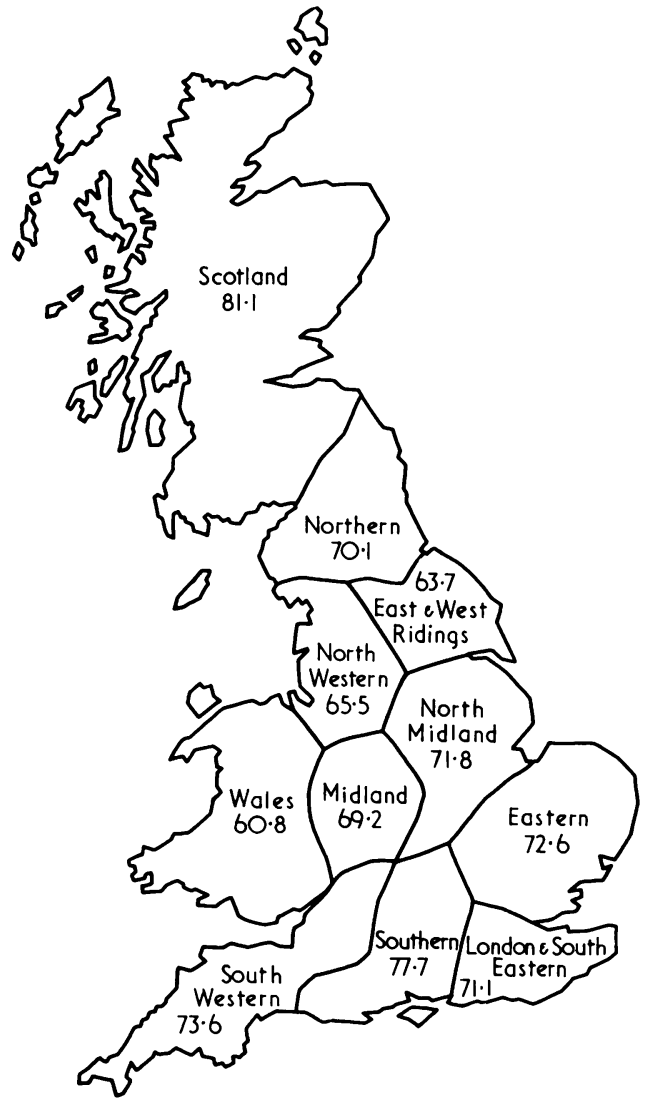

Percentages of girls who received rubella vaccine by region. 
girls receiving vaccine came from social classes III and IV whereas significantly fewer children from professional families (social classes I and II) and unskilled manual families (social class V) were reported to have been vaccinated (see table).

The uptake of rubella vaccine was analysed by type of school, and it was reported to have been given to $2978\left(72^{\circ}{ }^{\circ}\right)$ of 4118 girls attending comprehensive, grammar, and secondary modern schools and $69\left(68^{\circ}{ }^{\prime}\right)$ of 102 from direct grant schools. In contrast only $77\left(48^{\circ}{ }_{0}\right)$ of 160 girls attending independent schools had been vaccinated. This difference is significant $(\mathbf{P}<0.001)$.

Rubella vaccine uptake in schoolgirls by social class

\begin{tabular}{|c|c|c|c|}
\hline \multirow{2}{*}{ Social class } & \multicolumn{2}{|c|}{ Rubella immunisation } & \multirow{2}{*}{ Total } \\
\hline & $\begin{array}{l}\text { No }(" .) \text { of girls } \\
\text { vaccinated }\end{array}$ & $\begin{array}{l}\text { No }(", 1) \text { of girls } \\
\text { not vaccinated }\end{array}$ & \\
\hline $\begin{array}{ccc}\text { I } & \ldots & \ldots \\
\text { II } & \ldots & \\
\text { III non-manual } \\
\text { III manual }\end{array}$ & $\begin{array}{r}159(66 \cdot 8) \\
605(69 \cdot 1) \\
268(72 \cdot 8) \\
1318(74 \cdot 3) \\
426(72 \cdot 9) \\
132(66 \cdot 7) \\
35(61 \cdot 4) \\
678(67 \cdot 7)\end{array}$ & $\begin{array}{r}79(33 \cdot 2) \\
271(30 \cdot 9) \\
100(27 \cdot 2) \\
457(25 \cdot 7) \\
158(27 \cdot 1) \\
66(33 \cdot 3) \\
22(38 \cdot 6) \\
323(32 \cdot 3)\end{array}$ & $\begin{array}{r}238 \\
876 \\
368 \\
1775 \\
584 \\
198 \\
57 \\
1001\end{array}$ \\
\hline Total $\quad \ldots$ & $3621(71 \cdot 0)$ & $1476(29 \cdot 0)$ & 5097 \\
\hline
\end{tabular}

Test for difference in uptake between social classes $(\% ; \mathrm{DF}=1)$ : Social classes I and II $v$ social classes III and IV $10 \cdot 7(0 \cdot 01>\mathrm{P}>0 \cdot 001)$; social class $\mathrm{V} v$ social classes nificant).

\section{Discussion}

The overall uptake of rubella vaccine reported in this national sample of 16-year-old girls is $71^{\circ}{ }^{\prime}$. Although this is encouraging in the early days of the vaccine programme, this figure is not high enough for rubella vaccine to be completely effective in preventing severe handicaps due to rubella contracted for the first time during pregnancy. In October 1969 before the introduction of rubella vaccines, the level of natural immunity in women of childbearing age was about $80-90^{\circ}{ }_{0} .{ }^{7}$ The immunisation programme in Britain is selective, so that natural rubella will continue to occur in the community and any susceptible pregnant women would be at risk. If rubella immunisation is to be effective in such a programme in which males and young children are not vaccinated, vaccination of those at risk-that is, females-must increase this figure to almost $100^{\circ}{ }_{0}$. The regional disparity draws attention to the areas where more intensive vaccine campaigns must be launched. In Scotland, for example, where surveys are being carried out to evaluate the long-term efficacy of rubella vaccine, " the reported uptake is the highest.

One explanation for the low uptake of rubella vaccine in girls from professional families could be that they are more likely to attend independent schools and therefore to be excluded from the vaccination programme, which is implemented through the school health services. An analysis of rubella vaccine uptake by type of school supported this hypothesis. This finding might indicate a lack of parental awareness of the problem or a lack of structure for administering vaccine in independent schools. This is of particular concern since girls in this group have a higher susceptibility to rubella. ${ }^{9}$ A similarly low uptake of rubella vaccine in girls from unskilled manual families could be accounted for by a missed opportunity of vaccination owing to school absences, which are more frequent in this group, ${ }^{10}$ or alternatively failure to obtain parental consent, which is necessary for vaccination. Although girls from this background will have a higher incidence of protection from natural infection, this is not sufficiently high for us to remain complacent.

If a selective rubella vaccination programme is to succeed the vaccination of schoolgirls, who are a captive population, is essential. In Britain, vaccination of women of childbearing age should be only a temporary exercise aimed at protecting those who were over 14 when the school vaccination programme was introduced. Vaccination of adults is complicated by the need to carry out a preliminary test to identify those who are susceptible to rubella. It is important to do this so that appropriate advice can be given should a woman inadvertently become pregnant within eight weeks of vaccination, as the vaccine virus itself may damage the fetus. ${ }^{11}$

Congenital rubella is preventable but to achieve this objective the general public, particularly parents and the girls themselves, must be told of the severe complications that may result from getting rubella when pregnant. It is particularly important in obtaining parental consent to emphasise that a previous history of clinical rubella, even when it has been diagnosed by a doctor, correlates poorly with the serological state. Parents should be told that permission for vaccination should not be withheld on these grounds. Clearly if congenital rubella is to be prevented an increased effort must be made by those responsible for implementing the vaccination programme to ensure that a higher proportion of schoolgirls are vaccinated.

This work was financed by grants from the DHSS and DES to the National Children's Bureau. Dr W C Marshall is supported by a research grant from the Wellcome Trust.

\section{References}

${ }^{1}$ Department of Health and Social Security, Circular 9/70. London, DHSS, 1970

2 Department of Health and Social Security. Circular 17/72. London, DHSS, 1972.

3 Department of Health and Social Security. Circular 1/74. London, DHSS, 1974.

${ }^{4}$ Davie, R, Butler, N, and Goldstein, M, From Birth to Seven. London, Longman, 1974. In association with the National Children's Bureau.

${ }^{5}$ Britain's Sixteen-Year-Olds, ed K Fogelman. London, National Children's Bureau, 1976.

${ }^{6}$ Registrar General, Classification of Occupation, London, HMSO, 1966.

${ }^{7}$ Marshall, W C, Symposia Series in immunobiological Standardization, $1969,2,68$.

8 Zeally, H, British fournal of Preventive and Social Medicine, 1974, 28, 54.

9 Dudgeon, J A, et al, Practitioner, 1971, 207, 782.

${ }^{10}$ Fogelman, K, and Richardson, K, School attendance: some results from the National Child Development Study in 'Truancy', ed Barry Turner. London, Ward Lock Education, 1974.

11 Modlin, J F, et al, New England fournal of Medicine, 1976, 1, 972.

(Accepted 7 December 1976)

ONE HUNDRED YEARS AGO Emma B, aged 19, was admitted on January 11th, complaining of intense pain in her left ear. Thirteen years ago, whilst at play, another child put a small sandstone into the patient's ear. She was at once taken to a medical man, who attempted to remove the foreign body, but failed. The patient complained of pain from time to time, and also of deafness in that ear; but it was not until eighteen months ago that she again applied for surgical treatment. During this time, she had been seen by several surgeons and had received temporary relief. On examining the ear by a speculum and reflected light, a glistening white body was discerned close to the membrana tympani. A lotion of glycerine and laudanum was used to relieve the pain; and, on the 15th, with Dr Woodhouse's assistance (under whose care the patient was admitted), removal was attempted. When the foreign body was touched by a probe, or any attempt made to remove it with forceps, the patient complained of great pain. The pinna being well retracted, the ear was syringed with warm soap and water, and, in about ten minutes, the foreign body appeared at the external orifice. It was a polished white stone of the size of a pea, and in shape resembling very much the trapezoid bone. After its removal, the pain entirely ceased and the hearing next day was normal. Although it cannot positively be stated that this stone could have not been removed by the ear-scoop, I think there would have been great risk of serious injury to the patient, and the pain would have been intense. The smoothness and shape of the stone, with the smaller extremity externally, rendered removal by forceps almost impossible, and the pain would also have been great. By syringing, the foreign body was removed without the slightest pain or risk. (British Medical fournal, 1877.) 